\title{
Etude de l'aptitude fromagère d'une préparation enzymatique coagulante thermolabile extraite de Mucor miehei
}

\author{
par \\ J. P. RAMET et F. WEBER* \\ (avec la collaboration technique de Y. GILLET)
}

\section{A. EXPERIMENTATION EN FABRICATION DE FROMAGE A PATE MOLLE DE TYPE CAMEMBERT}

\section{Introduction}

Depuis plusieurs années différents succédanés ont été proposés en remplacement de la présure de veau traditionnellement utilisée en fromagerie. De nombreux travaux [11, 12,14] ont montré que l'activité protéolytique de ces nouveaux agents coagulants diffèrent de celle de la présure par leur intensité et leur spécificité et qu'ils ne présentent pas la même sensibilité aux variations de facteurs de milieu. Lors de la fabrication fromagère, ces propriétés spécifiques induisent directement ou indirectement des modalités de coagulation, d'égouttage et d'affinage qui nécessitent une adaptation des procédés de fabrication classiques [16-17], ces derniers étant en effet conditionnés en grande partie par les caractéristiques d'activité de la préparation coagulante particulière, la présure, utilisée jusqu'ici.

Ces études ont en outre révélé que l'élimination dans le lactosérum des enzymes coagulantes d'origine fongique n'est pas identique à celle de la présure, la proportion d'enzyme retenue dans le fromage étant dépendante de la nature de l'enzyme et du $\mathrm{pH}$ du milieu $[8,10]$. Par ailleurs, ces protéases fongiques se caractérisent par une thermorésistance spécifique : l'enzyme d'Endothia parasitica possède une résistance thermique voisine de la présure, les enzymes de Mucor pusillus et de Mucor miehei possèdent au

\footnotetext{
* Laboratoire de Science et Technologie des Aliments, Institut National Polytechnique de Lorraine, Ecole Nationale Supérieure d'Agronomie et des Industries Alimentaires (E.N.S.A.I.A.), 32, rue Ste-Catherine - 54000 Nancy (France).
} 
contraire une température d'inactivation thermique beaucoup plus élevée qui croît avec l'abaissement du $\mathrm{pH}[2,9,21]$. De ce fait les lactosérums issus de fromages fabriqués avec ces deux protéases peuvent renfermer une part non négligeable d'enzyme encore active. Cette activité peut persister après traitement thermique et séchage et se manifester par la coagulation accidentelle d'aliments lactés reconstitués renfermant ces poudres de lactosérums. Ce type d'incident a été signalé en particulier avec des préparations enzymatiques coagulantes de Mucor miehei qui possèdent une thermorésistance élevée $[219,21]$.

Afin de remédier à ces inconvénients, les laboratoires spécialisés ont proposé récemment de nouvelles formes thermolabiles de préparations coagulantes obtenues par modification des techniques de purification. Aussi il nous a paru intéressant d'étudier l'aptitude fromagère de ces nouveaux coagulants en les comparant à celle de la présure de veau.

Le présent travail résume nos observations relatives à l'utilisation d'une préparation commercialisée par la Division Carlin-Marschall des Laboratoires Miles sous la dénomination Marzyme II. Une première publication traitera des fabrications expérimentales de pâtes molles de type Camembert, une seconde sera consacrée aux résultats obtenus en fabrication de pâtes pressées de type Saint-Paulin.

\section{Matériel et méthodes}

\section{II.1. FABRICATION DU CAMEMBERT}

Les fabrications expérimentales ont été réalisées dans les ateliers pilotes de l'E.N.S.A.I.A. selon le procédé classique en bassines et une technique traditionnelle. Chaque série d'essais a été menée en parallèle et répétée trois fois ; leurs conditions particulières ont été les suivantes :

Préparation du lait

Lait frais réfrigéré : $24 \mathrm{~h}-4^{\circ} \mathrm{C}$.

Pasteurisation : $75^{\circ} \mathrm{C}-15 \mathrm{~s}$.

Standardisation : M.G. : $27 \mathrm{~g} / \mathrm{kg}$.

Addition de $\mathrm{CaCl}_{2}, 2 \mathrm{H}_{2} \mathrm{O}: 10 \mathrm{~g} / 100 \mathrm{~kg}$ lait.

Ensemencement en ferments lactiques Carlin-Marschall. $\mathrm{HM}_{2}$ type 300 LDS.

Ensemencement en Penicillium caseicolum, Lactolabo : 1 dose $20 \mathrm{~kg}$ de lait.

Maturation du lait avant emprésurage : $30 \mathrm{~min}-35^{\circ} \mathrm{C}$.

Coagulation du lait

Poids de lait par essai : $20 \mathrm{~kg}$. 
Température à l'emprésurage : $35^{\circ} \mathrm{C}$.

$\mathrm{pH}$ du lait à l'emprésurage : 6,50.

Enzymes coagulantes :

Témoin : présure de veau Carlin-Marschall, force : $1 / 10000$, dose $25 \mathrm{ml} / 100 \mathrm{~kg}$ lait.

Essai : Marzyme II, force 1/10 000, dose : $25 \mathrm{ml} / 100 \mathrm{~kg}$ lait.

\section{Egouttage}

Tranchage du coagulum en lanières de section : $3 \times 3 \mathrm{~cm}$.

Repos sous sérum après tranchage : $30 \mathrm{~min}$.

Moulage à la louche en moules inox. format Camembert.

Egouttage en moules :

Salle : température, durée : $28^{\circ} \mathrm{C}-5 \mathrm{~h}, 22^{\circ} \mathrm{C}-16 \mathrm{~h}$.

Hygrométrie 90 p. 100

Fromage : trois retournements : $3 \mathrm{~h}, 5 \mathrm{~h}, 10 \mathrm{~h}$ après moulage ; pesée et prise d'échantillon pour analyse (M.G., EST) après $22 \mathrm{~h}$ d'égouttage.

\section{Saumurage}

Concentration en $\mathrm{NaCl}: 300$ p. $1000 ; \mathrm{t}: 15^{\circ} \mathrm{C} ; \mathrm{pH}: 4,5$; durée : $45 \mathrm{~min}$.

\section{Affinage}

Ressuyage : $6 \mathrm{~h}$ après sortie de saumure.

Pulvérisation d'une suspension de spores de Penicillium caseicolum type superactif Lactolabo.

Conditions : température : $14^{\circ} \mathrm{C}$; hygrométrie : 90 p. 100 ; durée : $30 \mathrm{j}$.

Retournements sur claies tous les $4 \mathrm{j}$.

Emballages après $15 \mathrm{j}$ sous papier paraffiné.

\section{II.2. MÉthodes ANALYTiQUeS}

\section{II.2.1 Mesures rhéologiques}

L'évolution des propriétés rhéologiques des coagulums obtenus avec chacune des enzymes coagulantes a été suivie à l'aide du torsiomètre NIRD-PLINT modifié $[15,17,18]$. Le milieu utilisé est un lait écrémé non ensemencé en ferments lactiques. A l'expérience, ce substrat s'est avéré mieux adapté que le lait frais gras pour mesurer les variations fines de rigidité du gel ; l'absence de matière grasse donne un meilleur développement de la fermeté et la suppression du processus fermentaire diminue la variabilité des mesures ; le comportement rhéologique lié à l'activité enzymatique apparaît donc plus clairement. 
Les conditions particulières de coagulation sont les suivantes :

Substrat

Lait écrémé reconstitué à 10 p. 100 à partir d'une poudre "low-heat ".

$\mathrm{CaCl}_{2}, 2 \mathrm{H}_{2} \mathrm{O}: 10 \mathrm{~g} / 100 \mathrm{~kg}$ lait.

Pas d'addition de ferments lactiques.

Quantité : $20 \mathrm{~kg}$ par essai.

\section{Température}

$35^{\circ} \mathrm{C}$ maintenue constante par bain-marie thermostaté.

$\mathrm{pH}: 6,50$ ajusté par acide lactique.

Préparations coagulantes :

Témoin : présure de veau Carlin-Marschall, force : $1 / 10000$, dose $25 \mathrm{ml} / 100 \mathrm{~kg}$ lait.

Marzyme : dose ajustée pour avoir le même temps de floculation que le témoin dans les conditions de milieu à l'emprésurage.

\section{II.2.2. Caractérisation de la synérèse du coagulum}

Les cinétiques de la synérèse du coagulum et de l'acidification du lactosérum ont été suivies pendant toute la durée de l'égouttage en moules. En fin d'égouttage les compositions moyennes des lactosérums et des fromages ont été mesurées et les rendements fromagers établis. Les méthodes d'analyses classiques utilisées ont été les suivantes :

Acidité : méthode Dornic.

Matière grasse des laits et lactosérums : méthode Gerber.

Matière grasse des fromages : méthode Van-Gulik.

Extrait sec : méthode à l'étuve $102^{\circ} \mathrm{C}$ jusqu'à poids constant.

Fractions azotées: méthode Microkjeldhal. Technique Buchi.

\section{II.2.3. Caractérisation de l'affinage du fromage}

Au cours de l'affinage, la protéolyse de la pâte a été mesurée à différents moments de la maturation par estimation, par la méthode Microkjeldhal des fractions azotées libérées : Azote soluble (NS) - Azote non protéique (NPN). Par ailleurs l'évolution de l'extrait sec a été suivie et des examens organoleptiques ont été pratiqués par dégustateurs qualifiés selon la méthode du test triangulaire.

\section{Résultats, discussion}

\section{III.1. Coagulation}

L'évolution de la fermeté du coagulum est légèrement moins rapide dans les premières minutes suivant la floculation pour les 


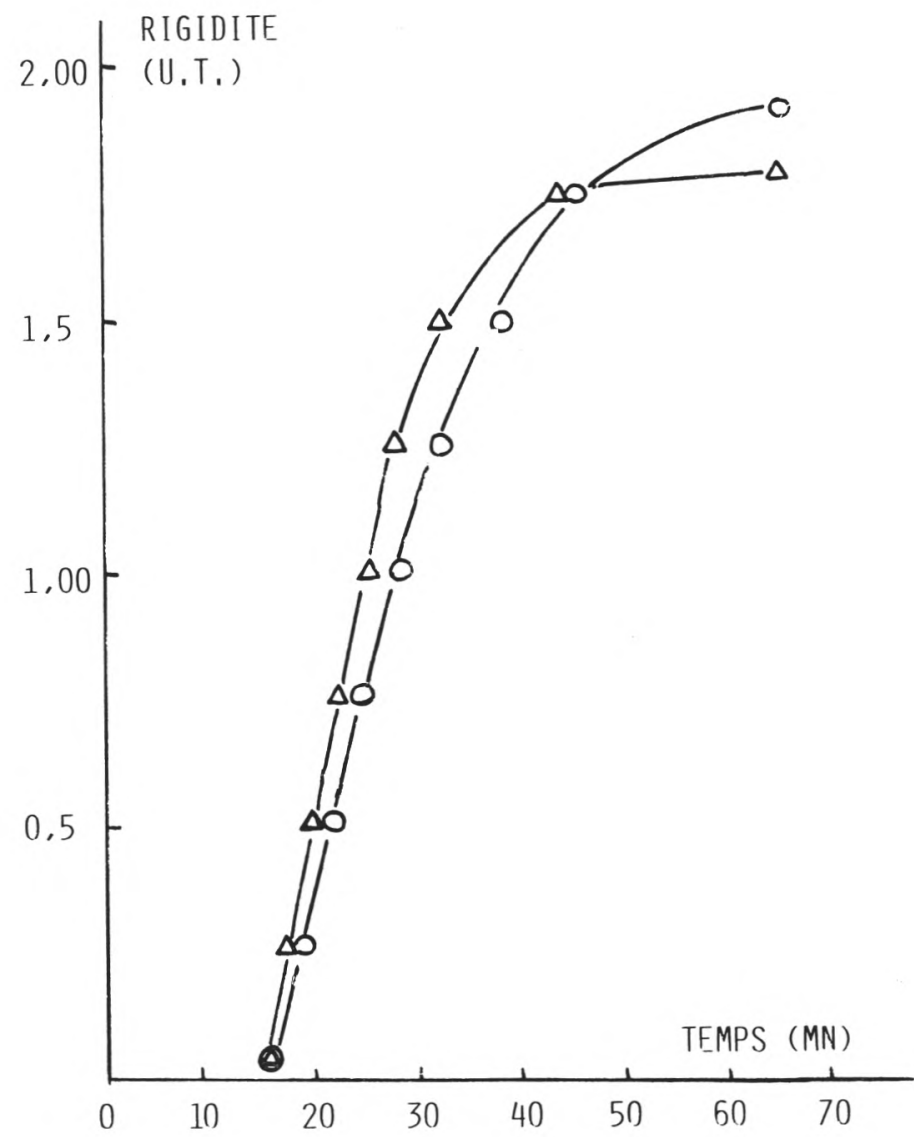

fig. 1

Evolution de la rigidité du coagulum

Conditions de milieu : lait reconstitué : 10 p. $100, \mathrm{CaCl}_{2}: 10 \mathrm{~g} / 100 \mathrm{~kg}$ lait, $\mathrm{t}: 35^{\circ} \mathrm{C}, \mathrm{pH}: 6,48$, [enzyme] : $25 \mathrm{ml} / 100 \mathrm{~kg}$ lait, U.T. : unité torsiomètre.

$\triangle \longrightarrow$ Présure.

○—— Enzyme Mucor miehei.

gels obtenus avec Marzyme (fig. 1). Après $45 \mathrm{~min}$, la fermeté devient supérieure à celle observée pour le coagulum témoin.

Ces cinétiques rhéologiques sont en accord avec l'évolution observée par ailleurs avec les préparations coagulantes de Mucor miehei où l'on assiste à un durcissement initial plus lent du gel [17] 


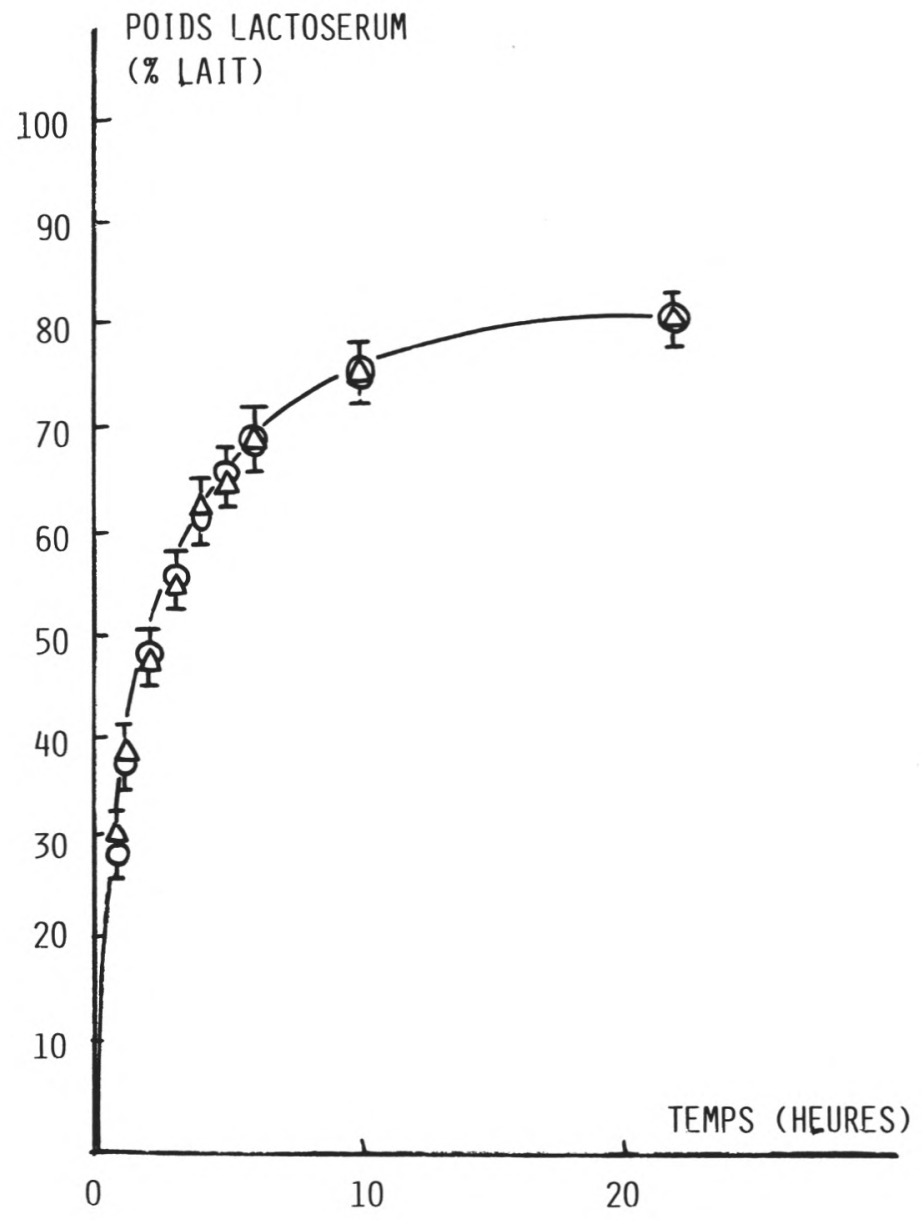

fig. 2

Evolution de l'égouttage du lactosérum du Camembert

$\triangle \longrightarrow$ Présure.

○—— Enzyme Mucor miehei.

Il s'agit d'un comportement rhéologique particulier probablement en relation avec l'action de la protéolyse qui induit un mode spécifique de structuration du gel $[16,18]$.

\section{III.2. Egouttage}

La comparaison des courbes moyennes d'égouttage (fig. 2) et d'acidification (fig. 3) des lactosérums ne montre aucune différence 


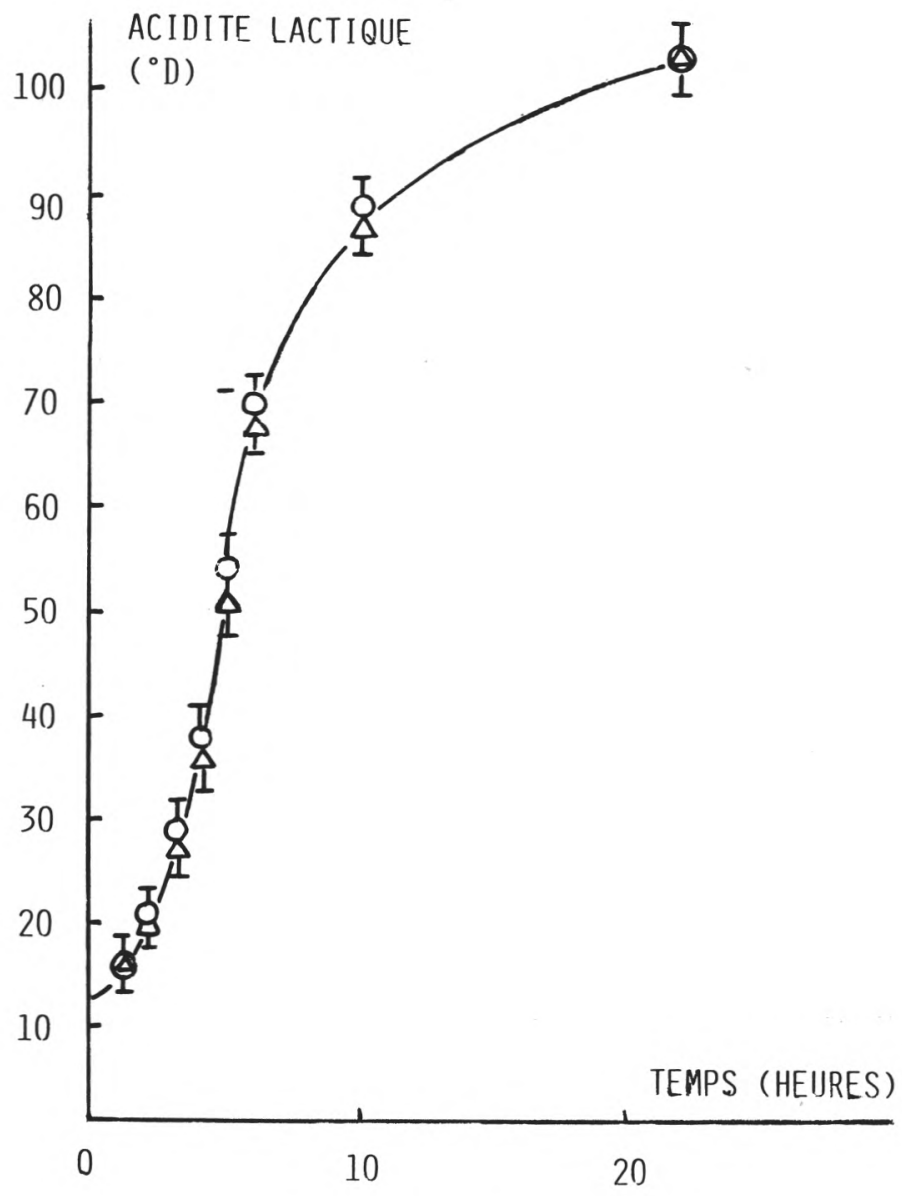

fig. 3

Evolution de l'acidification en lactosérum du Camembert pendant l'égouttage

$\triangle \longrightarrow \triangle$ Présure.

○—— Enzyme Mucor miehei.

significative avec les deux types de préparation coagulante utilisés. Il en est de même des rendements fromagers exprimés en poids sec et en poids frais (tab. 1).

Les variations dans la composition en matière sèche et en fractions azotées des lactosérums sont très faibles et non significatives au seuil de 95 p. 100 (tab. 2) ; elles confirment la similitude des modalités de l'égouttage. 


\section{TABLEAU 1}

Rendements fromagers

\begin{tabular}{|c|c|c|c|c|}
\hline & $\overline{\mathbf{M}}_{\mathrm{T}}$ & $\sigma$ & $\overline{\mathbf{M}}_{\mathrm{E}}$ & $\sigma$ \\
\hline Rendement frais & 16,75 & 0,35 & 16,90 & 0,65 \\
\hline $\begin{array}{l}\text { Rendement sec } \\
\text { (kg/100 kg lait) }\end{array}$ & 6,020 & 0,127 & 6,168 & 0,237 \\
\hline $\bar{M}:$ Moyenne & ssai & $\mathrm{T}: \mathrm{T}$ & & $\sigma:$ Ecart-type \\
\hline
\end{tabular}

TABLEAU 2

Composition des lactosérums Camembert

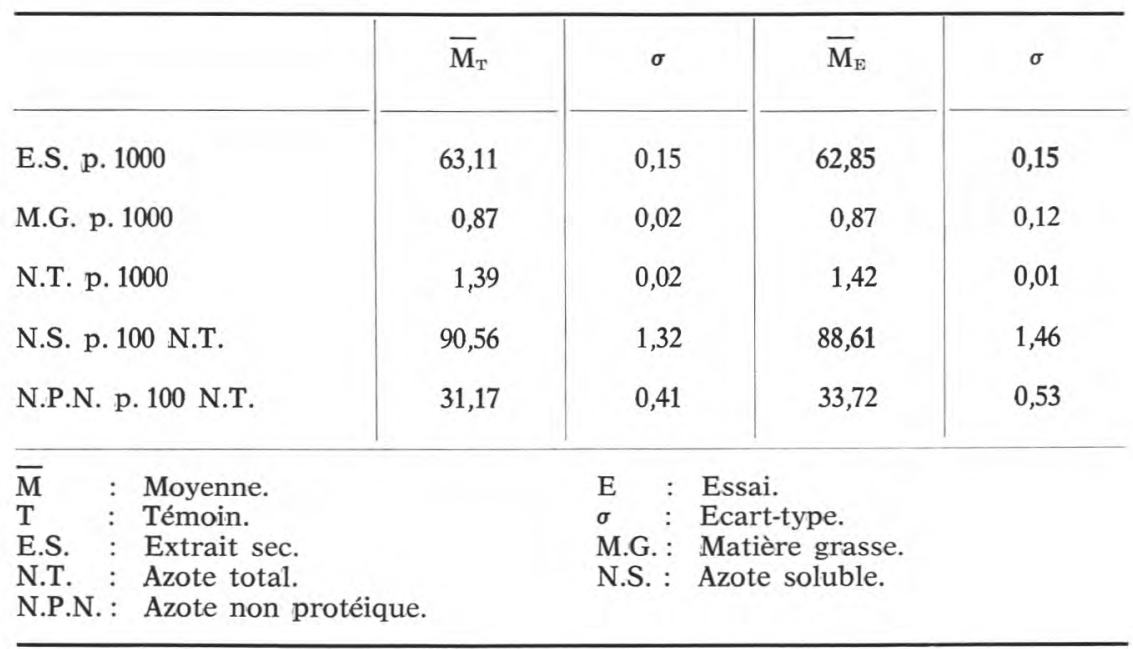

L'ensemble de ces résultats montre que l'activité protéolytique de la préparation de Marzyme II est très voisine de celle de la présure. Contrairement aux observations faites avec d'autres protéases coagulantes très actives, il n'y a pas de baisse des rendements fromagers par solubilisation des protéines lactées $[11,12,14]$.

L'acidification, qui généralement est activée lorsque des résidus de protéolyse sont présents dans le milieu et stimulent le développement des bactéries lactiques $[5,6,9,16]$, reste dans le cas présent semblable; ceci confirme le caractère très voisin de la protéo- 


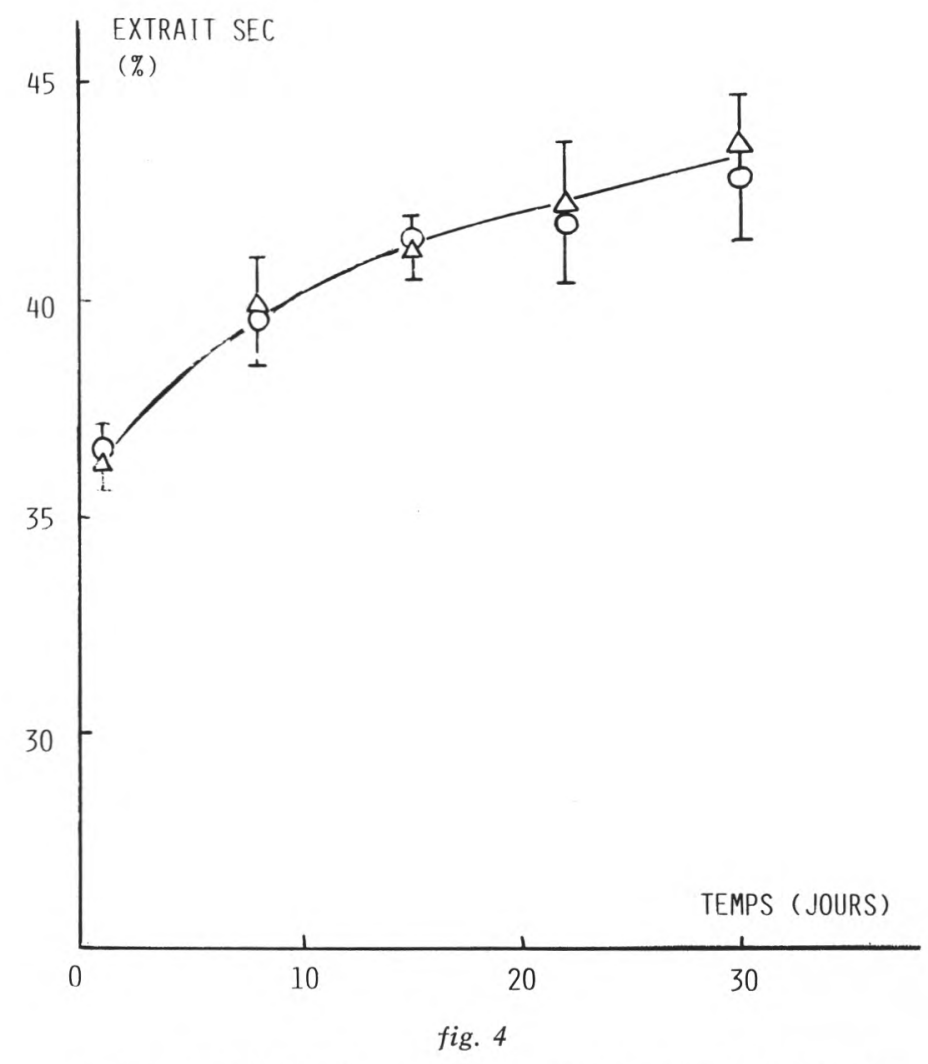

Evolution de l'extrait sec du Camembert pendant l'affinage

$\triangle \longrightarrow$ Présure.

○—— Enzyme Mucor miehei.

lyse engendrée par la présure et la nouvelle préparation coagulante de Mucor miehei étudiée.

\section{III.3. AfFINAGE}

Au cours de la maturation, le développement de Penicillium caseicolum est homogène et identique sur les deux types de fromages ; les pertes d'eau par dessiccation des fromages témoins et expérimentaux sont du même ordre (fig. 4). L'évolution de la composition azotée des fromages montre une grande similitude (fig. 5).

Ces résultats sont confirmés par l'analyse sensorielle qui a révélé des caractères organoleptiques comparables pour les deux types 


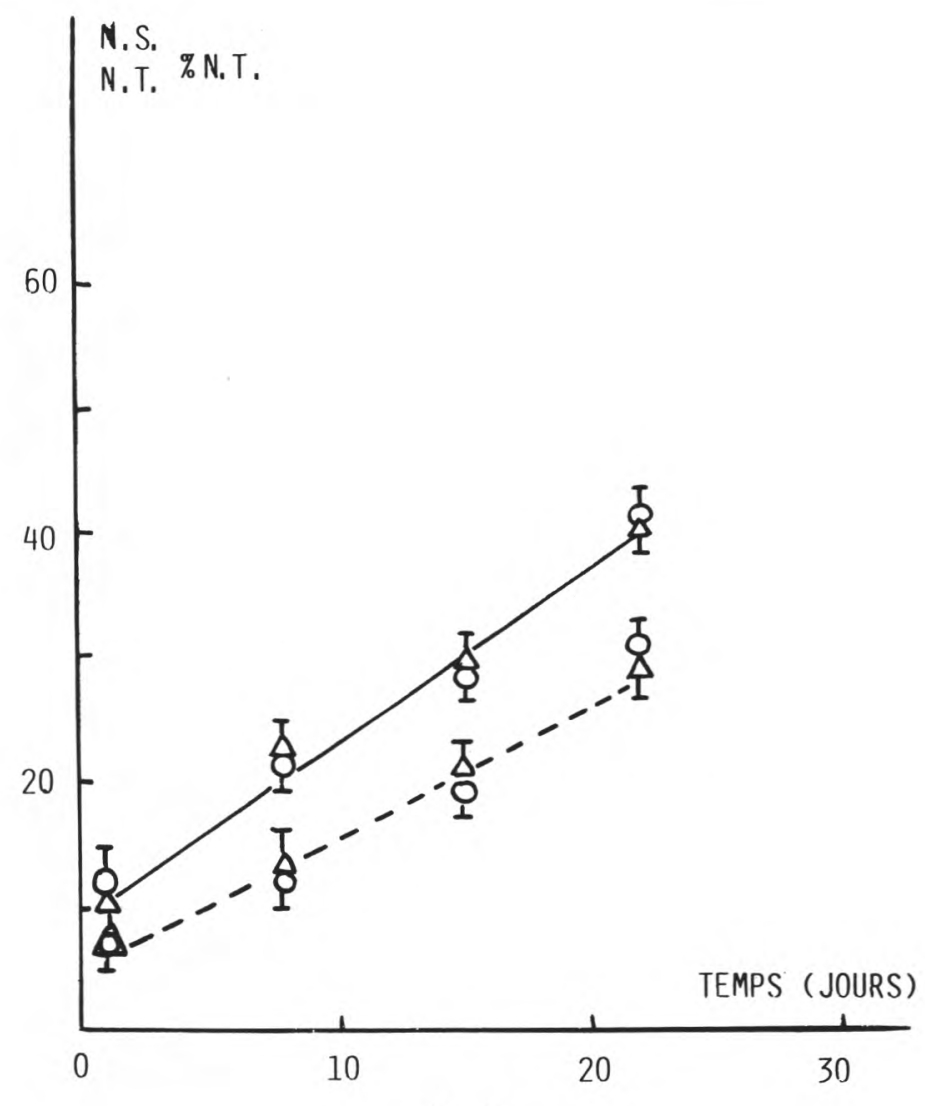

fig. 5

Evolution de la protéolyse du Camembert pendant l'affinage

$\triangle \longrightarrow$ Présure.

N.S.

○—— Enzyme Mucor miehei.

N.P.N.

de fromage. La bonne qualité du goût et la texture onctueuse ont été remarquées par l'ensemble des dégustateurs ; aucune amertume n'a été décelée aux différents stades de l'affinage.

Il apparaît donc que les modalités de la maturation se déroulent de la même manière pour les fromages fabriqués avec les deux types de préparation coagulante. Contrairement aux observations faites par des auteurs sur l'affinage des fromages fabriqués à l'aide d'autres préparations enzymatiques coagulantes de Mucor miehei [3], aucune accélération de la protéolyse n'a été relevée ; il est donc logique de penser que la réaction tertiaire de la nouvelle enzyme 
sur la caséine est équivalente à celle de la présure et plus faible que celle généralement observée avec les enzymes de Mucor miehei non thermolabiles $[1,4,7,13,20]$; il s'agit probablement des conséquences du mode particulier de purification de cette nouvelle préparation coagulante.

\section{Conclusion}

Il ressort donc de l'ensemble de ces résultats que l'utilisation de la nouvelle préparation enzymatique coagulante de Mucor miehei, Marzyme II, en remplacement de la présure de veau, ne modifie pas les modalités habituelles de la fabrication de fromages de type Camembert, ni les caractéristiques physico-chimiques et organoleptiques des produits finis.

\section{Rés u m é}

L'aptitude fromagère d'une nouvelle préparation coagulante thermolabile extraite de Mucor miehei est comparable à celle de la présure de veau. Les modalités de la fabrication de fromages de type Camembert ne sont pas modifiées par rapport à celles du procédé classique, en particulier les rendements fromagers et les qualités organoleptiques des produits affinés sont semblables.

\section{S u m m a r y}

\section{STUDY OF CHEESEMAKING ABILITY OF A THERMOSENSITIVE MILK-CLOTTING ENZYME OF MUCOR MIEHEI}

Technological properties of a new thermosensitive milk-clotting enzyme of Mucor miehei are similar to those observed with calf rennet. Compared to standard pattern of production, processing, yield and organoleptic quality of Camembert cheese are unmodified.

\section{Zusammenfassung}

Die technologischen Eigenschaften eines neues mikrobiologischen Lab von Mucor miehei sind dem tierischen Lab ähnlich. Die Käseherstellung, der Ertrag und die organoleptische Qualität wurden für Kamembert unter üblichen Bedingungen durchgeführt.

Reçu pour publication en février 1981.

\section{Bibliographie}

[1] Alais (C.) et Lagrange (A.) (1972). - Etude biochimique d'une protéase coagulante produite par Mucor miehei. Le Lait, 52, 407-427.

[2] Aoudjit (A.) (1977). - Etude de la thermorésistance de quelques enzymes coagulantes de fromagerie. Thèse Université de Nancy. 
[3] BenKe (V.) und Siewert (R.) (1969). - Untersuchungen zur Verwendung von $\mathrm{Lab}$ aus Mucor miehei zur Käseherstellung. Kieler Milchwirt. Ber., 23, 57-68.

[4] CARINi (J.), Lodi (R.) i Todesco (R.) (1973). - I cagli microbia caratteristiche nella degradazione della caseina e loro impiego nelle caseificazione die fromaggio "Crescenza». Il Latte, 47, 1, 13-22.

[5] Desmazeaud (M.) et Devoyod (J. J.) (1970). - Activité stimulante des microcoques caséolytiques sur les bactéries lactiques. Ann. Biol., Bioch., Biophys., $10,413-430$.

[6] Garvie (E. I.) and Mabitt (L. A.) (1956). - Acid production in milk starter cultures. The effect of peptone and other stimulatory substances. J. Dairy Res., 23, 3, 305-314.

[7] Hansen (R.) (1970). - Dégradation de la caséine au moyen de différentes enzymes provoquant la coagulation du lait. $18^{\mathrm{e}}$ Congr. Int. Lait., 1, F, 53.

[8] Harper (W. J.) and LeE (C. R.) (1975). - Residual coagulants in whey. I. Food Sci., 40, 282.

[9] Havlova (J.) and Dolezalek (J.) (1973), - Effect of various microbial rennets on acidifying activity of lactic acid bacteria of importance to dairy technology. Dairy Sci. Abst., 35, 9, 364.

[10] Holmes (D. G.), Duersch (J. W.) and Ernstrom (C. A.) (1977) . - Distribution of milk clotting enzymes between curd and whey and their survival during Cheddar cheesemaking. J. Dairy Sci., 60, 682.

[11] Martens (R.) et Naudts (1973). - Produits de remplacement de la présure de veau. Bull. Ann. F.I.L., doc. $\mathrm{n}^{\circ} 74$.

[12] Naudts (M.) (1969). - Les différents types de présure, Bull. Ann. F.I.L., partie VII.

[13] Paquet (D.) et Alais (C.) (1978). - Action de protéases fongiques sur la caséine bovine et ses constituants. Milchwissenschaft, 32, 87-90.

[14] Phelan (J. A.) (1973), - Laboratory and field tests on new milk coagulants. Dairy Ind., 38 (9), 418-419, 422-423.

[15] Plint (M. A.), Burnett (J.) and Scott-Blaik (G. W.) (1967), - Note on a improved dairy torsiometer. Dairy Ind., 32, 1, 104.

[16] Ramet (J. P.) (1976). - Etude de l'aptitude fromagère d'une enzyme coagulante extraite de Endothia parasitica. Cas des fromages à pâte molle et à pâte pressée. Thèse Université de Nancy.

[17] Ramet (J. P.) et Alais (C.) (1972). - Etude d'une protéase coagulante produite par Mucor miehei.

I. Utilisation de la Rennilase dans la fabrication de fromages à pâte molle. Le Lait, 52, 519-520, 654-663.

II. Utilisation de la Rennilase dans la fabrication de fromages à pâte pressee non cuite et de fromages à pâte pressée cuite. Le Lait, 52, 523$524,154-162$.

[18] Ramet (J.P.) et Weber (F.) (1980). - Contribution à l'étude de l'influence des facteurs de milieu sur la coagulation enzymatique du lait reconstitué. Le Lait, 60, 591-592, 1-13.

[19] RÉGNIER (J. M.) (1977). - Résistance thermique des enzymes coagulantes. Ann. Fals. Exp. chim., 70, (751), 165-175.

[20] VAN den PooRten (R.) and Weck (E.) (1972). - Breakdown of casein by rennet and microbial milk enzymes. Neth. Milk. Dairy J., 29, (2-3), 181-197.

[21] Thunell (R. K.) and Duersch (J. W.) (1979). - Thermal inactivation of residual milk clotting enzymes in whey. J. Dairy Sci., 62, 373-377. 